Check for updates

Cite this: RSC Adv., 2019, 9, 33883

Received 11th October 2019

Accepted 16th October 2019

DOI: 10.1039/c9ra08303k

rsc.li/rsc-advances

\title{
Synthesis and characterization of a $\mathrm{ZnGa}_{2} \mathrm{O}_{4}: \mathrm{Cr}^{3+}$ based aerogel $\dagger$
}

\author{
Ting Zhang, Ai Du, (D)* Chuanxiang Chen, Xiujie Ji, Bin Zhou, Jun Shen \\ and Zhihua Zhang
}

A $\mathrm{ZnGa}_{2} \mathrm{O}_{4}: \mathrm{Cr}^{3+}$-based aerogel was prepared by using polyacrylic acid (PAA) as a dispersant and propylene oxide (PO) as a crosslinking agent via $\mathrm{CO}_{2}$ supercritical drying. The results of $\mathrm{BET}$ and SEM show that there is a certain degree of macroporosity $(d>50 \mathrm{~nm})$ in the aerogel. It has a dendritic structure and the interior is relatively loose. EDS mapping illustrates that the elements $\mathrm{Zn}, \mathrm{Ga}$, and $\mathrm{Cr}$ are evenly distributed in the aerogel. In addition, the diffuse reflectance spectra and the emission spectrum of samples with different calcination temperatures were also characterized. Both demonstrated, when the calcination temperature is greater than $600{ }^{\circ} \mathrm{C}$, that the sample crystallizes and has a significant emission, which is consistent with the XRD and TG-DSG results. Finally, the $\mathrm{ZnGa}_{2} \mathrm{O}_{4}: \mathrm{Cr}^{3+}$-based aerogel also exhibits excellent long afterglow performance and high photocatalytic performance with $80.1 \%$ methylene blue (MB) degradation at $20 \mathrm{~min}$.

\section{Introduction}

As a self-activating new luminescent material, $\mathrm{ZnGa}_{2} \mathrm{O}_{4}$ has received extensive attention from researchers. It has excellent chemical stability and color purity. ${ }^{1-4}$ Therefore, this attractive oxide phosphor material is widely used for low-voltage cathodoluminescent and vacuum fluorescent displays, liquid crystal displays (LCD), field emission displays and electroluminescent devices. ${ }^{5-10} \mathrm{ZnGa}_{2} \mathrm{O}_{4}$ is an $\mathrm{AB}_{2} \mathrm{O}_{4}$ spinel-type crystal structure. ${ }^{4}$ In terms of luminescence properties, the optical bandgap is about $4.4 \mathrm{eV}$. In the $\mathrm{ZnGa}_{2} \mathrm{O}_{4}$ single crystal, there are many defects, and some intrinsic defects are generated during the calcination process. In addition, due to the small difference in ionic radius, they will directly enter each other's crystal lattice. In $\mathrm{ZnGa}_{2} \mathrm{O}_{4}$, about $3 \%$ of antisite defects exist, which makes it have excellent long afterglow. ${ }^{11,12}$

As a good luminescent material matrix, it shows various emission colors when doped with different transition metal ions or rare earth ions, such as $\mathrm{Cr}^{3+}, \mathrm{Mn}^{2+}, \mathrm{Eu}^{3+}$ or $\mathrm{Ce}^{3+} \cdot{ }^{2,3,13-15}$ The near-infrared luminescence of $\mathrm{Cr}^{3+}$ was reported as early as 1988, but the $\mathrm{Cr}^{3+}$ doped with $\mathrm{ZnGa}_{2} \mathrm{O}_{4}$ near-infrared luminescent material was rarely reported. The first report on near infrared-persistent luminescence in $\mathrm{Cr}^{3+}$ doped $\mathrm{ZnGa}_{2} \mathrm{O}_{4}$ by Bessière et al. in $2011 .{ }^{16} \mathrm{ZnGa}_{2} \mathrm{O}_{4}: \mathrm{Cr}^{3+}$ is a bright red emitting long-lasting phosphor when ultraviolet excited with the emission range of $650-750 \mathrm{~nm}$.

Shanghai Key Laboratory of Special Artificial Microstructure Materials and Technology, School of Physics Science and Engineering, Tongji University, Shanghai 200092, China. E-mail: duai@tongji.edu.cn; Tel: +86 2165986071

$\dagger$ Electronic supplementary information (ESI) available. See DOI: 10.1039/c9ra08303k
The reported $\mathrm{ZnGa}_{2} \mathrm{O}_{4}: \mathrm{Cr}^{3+}$ is mostly synthesized by high temperature solid state method. This method produces large particles, irregular morphology and sinter clustering. The researchers focused on finding a way to synthesize $\mathrm{ZnGa}_{2} \mathrm{O}_{4}$ :$\mathrm{Cr}^{3+}$ at low temperatures and even in solution. Under this condition, it is beneficial to adjust the shape of the material and control its size. The sol-gel method gives an excellent control over the stoichiometry, introducing dopant easily and allowing lower processing temperature compared to other methods. ${ }^{13}$ The citrate sol-gel technique is the most common. But its only can obtained nanopowders instead of monolith. And the sample density is larger, the pores are less and the pore size is small.

A new sol-gel method for preparation of $\mathrm{ZnGa}_{2} \mathrm{O}_{4}: \mathrm{Cr}^{3+}$ long afterglow materials. In this paper, PAA and PO are used as a dispersant and a crosslinking agent to prepare a $\mathrm{ZnGa}_{2} \mathrm{O}_{4}$ :$\mathrm{Cr}^{3+}$-based (with $\mathrm{ZnO}$ as the skeleton) aerogel. $\mathrm{ZnGa}_{2} \mathrm{O}_{4}: \mathrm{Cr}^{3+}$ has potential application value in bioprobe technology due to its excellent near-infrared long afterglow luminescence. The $\mathrm{ZnGa}_{2} \mathrm{O}_{4}: \mathrm{Cr}^{3+}$-based aerogel prepared by this method has more macropores, can be used as a drug carrier because of its sustained release effect. Also, monolith $\mathrm{ZnGa}_{2} \mathrm{O}_{4}: \mathrm{Cr}^{3+}$-based aerogel have a significant role in the field of hypervelocity particle capture. When space debris or comet particles impact this aerogel, as the depth of penetration increases, the aerogel heated temperature gradually decreases. Thus creating a temperature gradient on the track. Therefore, according to the difference of luminous intensity, the heating temperature at each position of the track can be derived. This is of great significance for solving the thermal interaction between hypervelocity particles and aerogels. 


\section{Experimental and characterizations}

\subsection{Materials}

$\mathrm{Zn}\left(\mathrm{NO}_{3}\right)_{2} \cdot 6 \mathrm{H}_{2} \mathrm{O}, \mathrm{Ga}\left(\mathrm{NO}_{3}\right)_{3} \cdot x \mathrm{H}_{2} \mathrm{O}, \mathrm{Gr}\left(\mathrm{NO}_{3}\right)_{3} \cdot 9 \mathrm{H}_{2} \mathrm{O}$, polyacrylic acid (PAA, $\left.\left(\mathrm{C}_{3} \mathrm{H}_{4} \mathrm{O}_{2}\right)_{n}\right)$, propylene oxide $\left(\mathrm{C}_{3} \mathrm{H}_{6} \mathrm{O}, \geq 99.5 \%\right)$, ethanol $(\geq 99.9 \%)$ were all purchased from Sinopharm Chemical Reagent Co., Ltd, Shanghai, China.

\subsection{Preparation of $\mathrm{ZnGa}_{2} \mathrm{O}_{4}: \mathrm{Cr}^{3+}$-based aerogels}

The $\mathrm{ZnGa}_{2} \mathrm{O}_{4}: \mathrm{Cr}^{3+}$-based gel was synthesized by sol-gel method using PAA as dispersant and $\mathrm{PO}$ as crosslinking agent. The $\mathrm{Zn}\left(\mathrm{NO}_{3}\right)_{2} \cdot 6 \mathrm{H}_{2} \mathrm{O}, \mathrm{Ga}\left(\mathrm{NO}_{3}\right)_{3} \cdot x \mathrm{H}_{2} \mathrm{O}$ and $\mathrm{Gr}\left(\mathrm{NO}_{3}\right)_{3} \cdot 9 \mathrm{H}_{2} \mathrm{O}$ were dissolved in ethanol at a molar ratio of $2: 1: 0.07$. After $15 \mathrm{~min}$ of stirring, the solution was light blue, $2 \mathrm{ml}$ of deionized water and $2.31 \mathrm{ml}$ of PAA were added to the solution. After stirring for another half an hour, $5 \mathrm{ml}$ of PO was added. Finally, the sol is placed at room temperature to gel. The gel was aged under airtight conditions for four days at room temperature and then soaked in ethanol for one week. Replaced with solvent ethanol three times, then carried out $\mathrm{CO}_{2}$ supercritical fluid drying. At last, $\mathrm{ZnGa}_{2} \mathrm{O}_{4}: \mathrm{Cr}^{3+}$-based aerogel was obtained. The dried sample was calcined in a muffle furnace at $500{ }^{\circ} \mathrm{C}, 600{ }^{\circ} \mathrm{C}$, $700{ }^{\circ} \mathrm{C}, 800{ }^{\circ} \mathrm{C}$ for $2 \mathrm{~h}$, respectively. The preparation process of the $\mathrm{ZnGa}_{2} \mathrm{O}_{4}: \mathrm{Cr}^{3+}$ aerogel (reference sample) with the atomic ratio of $\mathrm{Zn}: \mathrm{Ga}=1: 2$ is the same as above.

\subsection{Photocatalytic experiment}

Take $80 \mathrm{ml}$ of methylene blue (MB) solution with a concentration of $20 \mathrm{mg} \mathrm{L}^{-1}$ in a culture dish, and then add $20 \mathrm{mg}$ of aerogel powder samples. Place in the dark room for forty minutes to exclude the influence of adsorption on photocatalytic. Then, it was exposed to ultraviolet (UV) light for $100 \mathrm{~min}$, and the concentration of methylene blue in each sample was measured by spectrophotometer every 20 minutes. We have made a calibration curve for methylene blue. The relationship between absorbance and its concentration is: $A=$ $0.175 c+0.016$. The photocatalytic experiment of the reference sample is the same as above.

\subsection{Characterizations}

The microstructure and morphology of the $\mathrm{ZnGa}_{2} \mathrm{O}_{4}: \mathrm{Cr}^{3+}$-based aerogel was characterized by a scanning electron microscope (SEM, Philips-XL30FEG, Thermo Fisher Scientific Inc., Hillsboro, OR, USA). The Brunner-Emmett-Teller (BET, AUTOSORB1-MP, Quantachrome, Boynton Beach, FL, USA) was used to measure the pore size distribution and specific surface area of the aerogels. The samples with different calcination temperatures were also characterized by X-ray diffraction (XRD, X'PertPro MPD, Holland Panalytical). The infrared absorption spectroscopy of aerogel after calcined was measured by Fourier infrared spectrometer (FTIR, Tensor 27, Bruker, Germany). A synchronous thermal analyzer (TG, STA449C, Netzsch, Germany) was used for recording TG-DSC curves of the aerogel. Photoluminescence (PL) spectra were determined by a Hitachi F-4500 spectrofluorometer. The diffuse reflectance spectra were measured by ultraviolet-visible-infrared (UV-Vis-IR) spectrophotometer (JASCO V-570, JASCO, Kyoto, Japan). (It is important to emphasize, the wavelength of the diffuse reflection detector is recorded according to the incident light wavelength.)

\section{Results and discussion}

Fig. 1(a) shows the appearance of $\mathrm{ZnGa}_{2} \mathrm{O}_{4}: \mathrm{Cr}^{3+}$-based aerogel, which has good formability with a density of about $215 \mathrm{mg}$ $\mathrm{cm}^{-3}$. Fig. 1(b) shows the SEM image. It can be seen that there are large holes, showing a dendritic structure and the interior is relatively loose. $\mathrm{N}_{2}$ adsorption-desorption isotherm and the pore size distribution of the aerogel are shown in Fig. 1(c). We can see that the pore size is widely distributed from big mesopores to macropores with an average value of $14.6 \mathrm{~nm}$. And the specific surface area is $420.3 \mathrm{~m}^{2} \mathrm{~g}^{-1}$. The isotherm of the $\mathrm{ZnGa}_{2} \mathrm{O}_{4}: \mathrm{Cr}^{3+}$-based aerogel is type-IV, which has distinct capillary condensation and evaporation steps characteristic of mesoporous materials $(d=2-50 \mathrm{~nm})$. There is no platform at high relative pressure, indicating a certain degree of macroporosity $(d>50 \mathrm{~nm}) .{ }^{17}$ It can also be seen from the pore size distribution image that the peak value is between $50-70 \mathrm{~nm}$. The hysteresis loop shape of the aerogel is type-H1, which is characterized by parallel and nearly vertical branches, indicating the presence of a cylindrical pore with narrow pore size distribution or a large number of spherical holes continuously stacked. ${ }^{18}$ Fig. S1(a) and (b) $\dagger$ show that the reference sample has poor formability compared with $\mathrm{ZnGa}_{2} \mathrm{O}_{4}: \mathrm{Cr}^{3+}$-based aerogel. And a larger pore size in reference sample as illustrated in Fig. S1(c). $\dagger$ Fig. 2 is the (a) TEM picture of $\mathrm{ZnGa}_{2} \mathrm{O}_{4}: \mathrm{Cr}^{3+}$-based aerogel and EDS mapping images of (b) Zn, (c) Ga and (d) $\mathrm{Cr}$ element. The atomic percentages of the elements $\mathrm{Zn}, \mathrm{Ga}$, and $\mathrm{Cr}$ are $63.11 \%, 28.71 \%, 8.18 \%$, respectively, and evenly distributed in the aerogel. The amounts of the $\mathrm{Zn}$ and $\mathrm{Ga}$ elements are basically the same as those mentioned in the experimental section.

Fig. 3 shows the XRD patterns of the samples with various calcined temperatures. It can be seen that the aerogel exhibits nanocrystalline properties after calcination at least $600{ }^{\circ} \mathrm{C}$, and the sample calcined at $500{ }^{\circ} \mathrm{C}$ is amorphous. The peaks of the curves in the Fig. 3 correspond to No. 30-1240 in the JCPDS document, indicating that the sample is a cubic crystal spinel structure. The sample has crystallized at $600{ }^{\circ} \mathrm{C}$ and a broad diffraction peak appears. As the calcination temperature increases, the diffraction peaks gradually become stronger and sharper. We attribute it to an increase of crystallinity. It can be seen from Fig. $\mathrm{S} 2 \dagger$ that the crystallization temperature of the reference sample increased from $600{ }^{\circ} \mathrm{C}$ to $700{ }^{\circ} \mathrm{C}$.

FTIR spectra of the $\mathrm{ZnGa}_{2} \mathrm{O}_{4}: \mathrm{Cr}^{3+}$-based aerogel calcined at various temperatures are shown in Fig. 4(a). The broad band at $3430 \mathrm{~cm}^{-1}$ is due to the stretching vibration of $\mathrm{H}_{2} \mathrm{O}$, indicating the existence of water absorbed in the samples. PAA commonly used as both a water absorbing agent and a dispersing agent. In this experiment, the aerogel prepared by using PAA as a dispersing agent is also easy to absorb water. The band at $1600 \mathrm{~cm}^{-1}$ represents the stretching vibrations of $\mathrm{COO}^{-}$groups of PAA. It shows that the sample contains impurities and the 

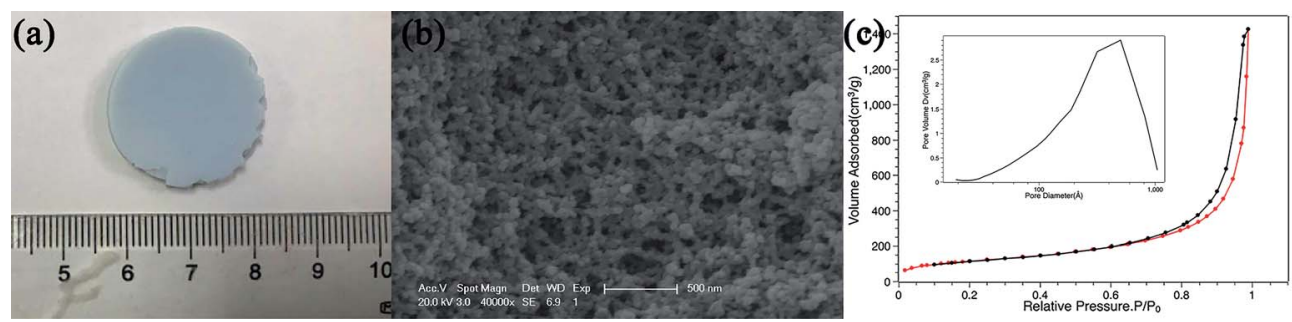

Fig. 1 (a) The appearance, (b) SEM picture and (c) the $\mathrm{N}_{2}$ adsorption-desorption isotherms of $\mathrm{ZnGa}_{2} \mathrm{O}_{4}$ : $\mathrm{Cr}^{3+}$-based aerogel, inset is the pore size distribution.

organic matter is not completely decomposed. The band between $1000 \mathrm{~cm}^{-1}$ to $1300 \mathrm{~cm}^{-1}$ is due to the vibration of the $\mathrm{NO}^{3-}$ group. With the increasing of temperature, the above mentioned bands became weaker. Since the aerogel is based on $\mathrm{ZnO}$, the $\mathrm{Zn}-\mathrm{O}$ adsorption peak $\left(589 \mathrm{~cm}^{-1}\right)$ appears in the infrared spectrum of all samples. When the temperature reaches $600{ }^{\circ} \mathrm{C}$, another adsorption peak appear at $420 \mathrm{~cm}^{-1}(\mathrm{Ga}-$ $\mathrm{O})$, which also indicating the formation of $\mathrm{ZnGa}_{2} \mathrm{O}_{4}$ nanocrystals. Unlike $\mathrm{ZnGa}_{2} \mathrm{O}_{4}: \mathrm{Cr}^{3+}$-based aerogel, there is no $\mathrm{Zn}-\mathrm{O}$ $\left(\sim 589 \mathrm{~cm}^{-1}\right)$ adsorption peak (Fig. S3(a)†) in the uncalcined reference sample. When the temperature reached $700{ }^{\circ} \mathrm{C}$, two adsorption peaks appeared at $\sim 586 \mathrm{~cm}^{-1}(\mathrm{Zn}-\mathrm{O})$ and $\sim 420 \mathrm{~cm}^{-1}$ (Ga-O), indicating the formation of $\mathrm{ZnGa}_{2} \mathrm{O}_{4}$ nanocrystals. Fig. 4(b) shows TG-DSG results of the aerogel. The decrease in mass within $100{ }^{\circ} \mathrm{C}$ is attributed to the evaporation of adsorbed moisture. In the range of $100{ }^{\circ} \mathrm{C}$ to $360^{\circ} \mathrm{C}$, it can be seen slight weight loss due to decomposition of some organic groups. The strong exothermic peak at $410{ }^{\circ} \mathrm{C}$ accompanied weight loss is mainly due to the decomposition of PAA and some residual organic matter. The sample at $600-800{ }^{\circ} \mathrm{C}$ is in the
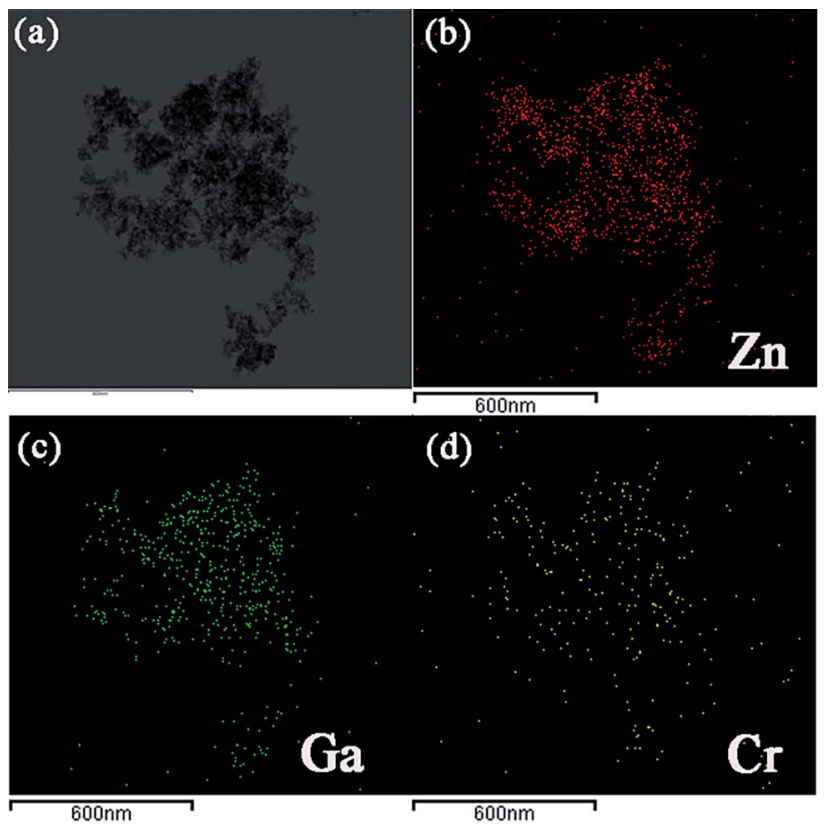

Fig. 2 The (a) TEM picture of $\mathrm{ZnGa}_{2} \mathrm{O}_{4}: \mathrm{Cr}^{3+}$-based aerogel and EDS mapping images of (b) $\mathrm{Zn}$, (c) $\mathrm{Ga}$ and (d) $\mathrm{Cr}$ element. endothermic process and the mass remains unchanged, indicating the formation of $\mathrm{ZnGa}_{2} \mathrm{O}_{4}$ nanocrystals. The crystallinity of the sample increases and the particles gradually increase during this process. However, an exothermic peak appeared at $900{ }^{\circ} \mathrm{C}$ should attribute to loss of $\mathrm{ZnO}$ during firing. The vapor pressure of ZnO is relatively high. ${ }^{15}$ But as shown in Fig. S3(b), $\dagger$ there is no excess $\mathrm{ZnO}$ in reference sample, so there is no exothermic peak at $900{ }^{\circ} \mathrm{C}$.

UV-visible diffuse reflectance spectra and the photoluminescence emission spectrum of the samples are shown in Fig. 5. The spectra of the samples both present two additional absorption bands at $550 \mathrm{~nm}$ and $430 \mathrm{~nm}$ which attributed to ${ }^{4} \mathrm{~A}_{2}$ $\left({ }^{4} \mathrm{~F}\right)-{ }^{4} \mathrm{~T}_{2}\left({ }^{4} \mathrm{~F}\right)$ and ${ }^{4} \mathrm{~A}_{2}\left({ }^{4} \mathrm{~F}\right)-{ }^{4} \mathrm{~T}_{1}\left({ }^{4} \mathrm{~F}\right)$ transitions of $\mathrm{Cr}^{3+}$, respectively. ${ }^{19,20}$ The third peak is about $260 \mathrm{~nm}$, we attribute this band to the spin-allowed ${ }^{4} \mathrm{~A}_{2}\left({ }^{4} \mathrm{~F}\right)-{ }^{4} \mathrm{~T}_{1}\left({ }^{4} \mathrm{P}\right)$ absorption transition of $\mathrm{Cr}^{3+}$. Three excitation peaks attributed to three $\mathrm{d}-\mathrm{d}$ absorption bands of $\mathrm{Cr}^{3+} .{ }^{21}$ From Fig. S4(a), $\dagger$ the UV-visible diffuse reflectance spectra of reference sample is the same as $\mathrm{ZnGa}_{2} \mathrm{O}_{4}: \mathrm{Cr}^{3+}$ based aerogel. It can be seen from the PL emission spectrum that the sample starts to glow after being calcined at $600{ }^{\circ} \mathrm{C}$. This is consistent with the XRD results. Therefore, the UVvisible spectrum of the sample calcined at $500{ }^{\circ} \mathrm{C}$ cannot be excited. The higher the calcination temperature, the greater the luminous intensity. It can be seen from the Fig. 5(b) that the sample has a broad emission peak with a peak value of $696 \mathrm{~nm}$.

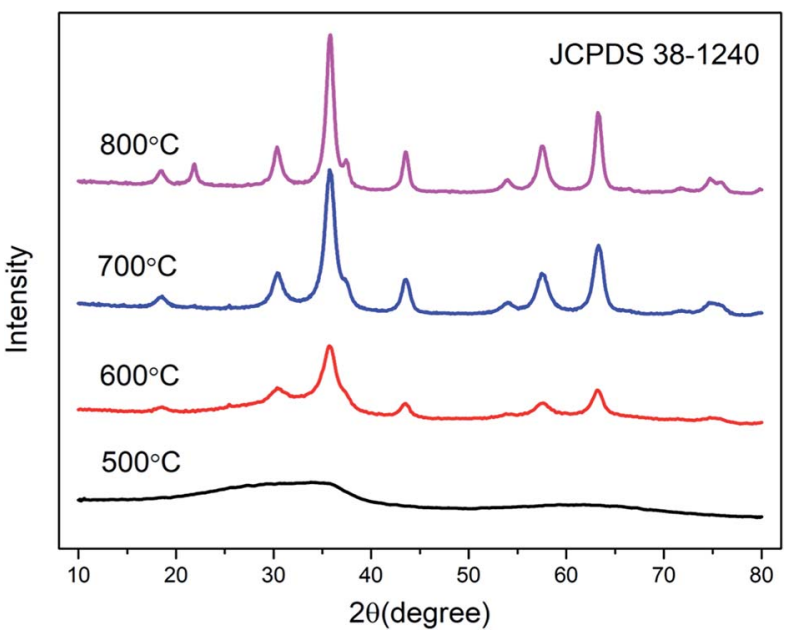

Fig. 3 XRD patterns of $\mathrm{ZnGa}_{2} \mathrm{O}_{4}: \mathrm{Cr}^{3+}$-based aerogel as a function of calcined temperature. 

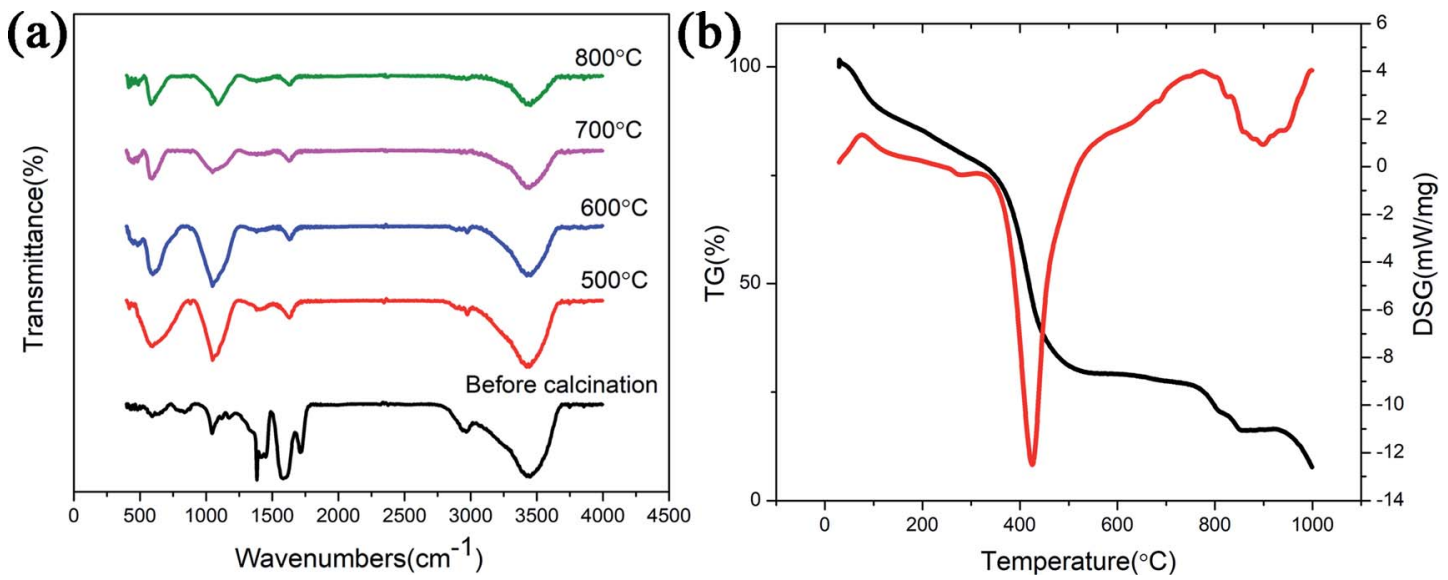

Fig. 4 (a) FTIR spectra as a function of calcined temperature; (b) TG-DSG result of the $\mathrm{ZnGa}_{2} \mathrm{O}_{4}: \mathrm{Cr}^{3+}$-based aerogel before calcined.

This typical emission peak is attributed to the ${ }^{2} \mathrm{E}-{ }^{4} \mathrm{~A}_{2}$ transition of $\mathrm{Cr}^{3+}$ in the $\mathrm{ZnGa}_{2} \mathrm{O}_{4}$ luminescent matrix. ${ }^{22}$ The emission peak at $713 \mathrm{~nm}$ is ascribed to the short-range perturbations of the octahedral sites surrounding $\mathrm{Cr}^{3+}$. These perturbations are caused by crystal defects and can manifest in the form of separate bands. ${ }^{23,24}$ Fig. $\mathrm{S} 4(\mathrm{~b}) \dagger$ illustrates that the reference sample starts to glow after being calcined at $700{ }^{\circ} \mathrm{C}$. Unlike $\mathrm{ZnGa}_{2} \mathrm{O}_{4}: \mathrm{Cr}^{3+}$-based aerogel, $\mathrm{ZnGa}_{2} \mathrm{O}_{4}: \mathrm{Cr}^{3+}$ aerogels not have the emission peaks at $696 \mathrm{~nm}$ and $713 \mathrm{~nm}$, but a large span of light-emitting region at 700-950 nm. However, if aerogels are used in the field of hypervelocity particle capture, we prefer that materials emit red light instead of infrared. This makes it easy to observe the tracks with a microscope.

Since the luminescence intensity of the samples calcined at $800{ }^{\circ} \mathrm{C}$ is the highest, we have characterized its PL decay properties and as shown in Fig. 6(a). When the excitation light is removed, the fluorescence intensity drops to $1 / e$ of the maximum fluorescence intensity $I_{0}$ at the time of excitation, which is called the fluorescence lifetime $\tau$. The bi-exponential represents two types of radiation channels, one is the emission between the conduction band and the valence band, and the other is the defect emission. The decay curves can be well fitted with a bi-exponential equation as given in the following expression:

$$
I(t)=I_{0}+A_{1} \mathrm{e}^{-\frac{t}{\tau_{1}}}+A_{2} \mathrm{e}^{-\frac{t}{\tau_{2}}}
$$

where $I$ is the luminescence intensity at time $t, A_{1}$ and $A_{2}$ are constants, $\tau_{1}$ and $\tau_{2}$ are the decay times for the exponential components. The average lifetime $(\tau)$ can be determined using the following equation:

$$
\tau=\left(A_{1} \tau_{1}^{2}+A_{2} \tau_{2}^{2}\right) /\left(A_{1} \tau_{1}+A_{2} \tau_{2}\right)
$$

The fitting data is shown in Table 1 . The decay process of the long-lasting phosphorescence can be divided into two parts: the fast process and the slow process. And the decay time is mainly determined by the slow part. Fig. 6(b) illustrates the energy levels involved in the energy transfer mechanism between $\mathrm{ZnGa}_{2} \mathrm{O}_{4}$ and $\mathrm{Cr}^{3+}$ and the subsequent emission from $\mathrm{Cr}^{3+}$. The sample is excited by $254 \mathrm{~nm}$ UV light (high energy), and the incident photon is absorbed by the $\mathrm{ZnGa}_{2} \mathrm{O}_{4}$ (host), causing the electron to directly transition from the valence band to the conduction band. Electrons are transferred from the
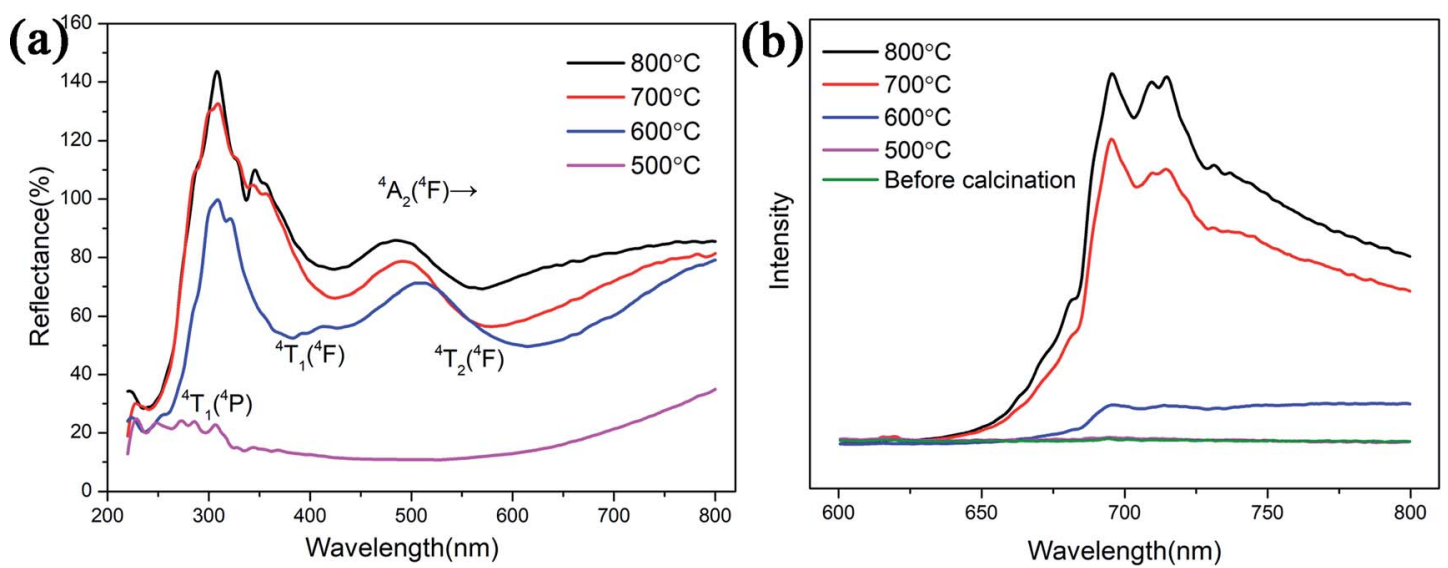

Fig. 5 (a) The UV-visible diffuse reflectance spectra and (b) the PL emission spectrum of the $\mathrm{ZnGa}_{2} \mathrm{O}_{4}: \mathrm{Cr}^{3+}$-based aerogels with different calcination temperatures. 

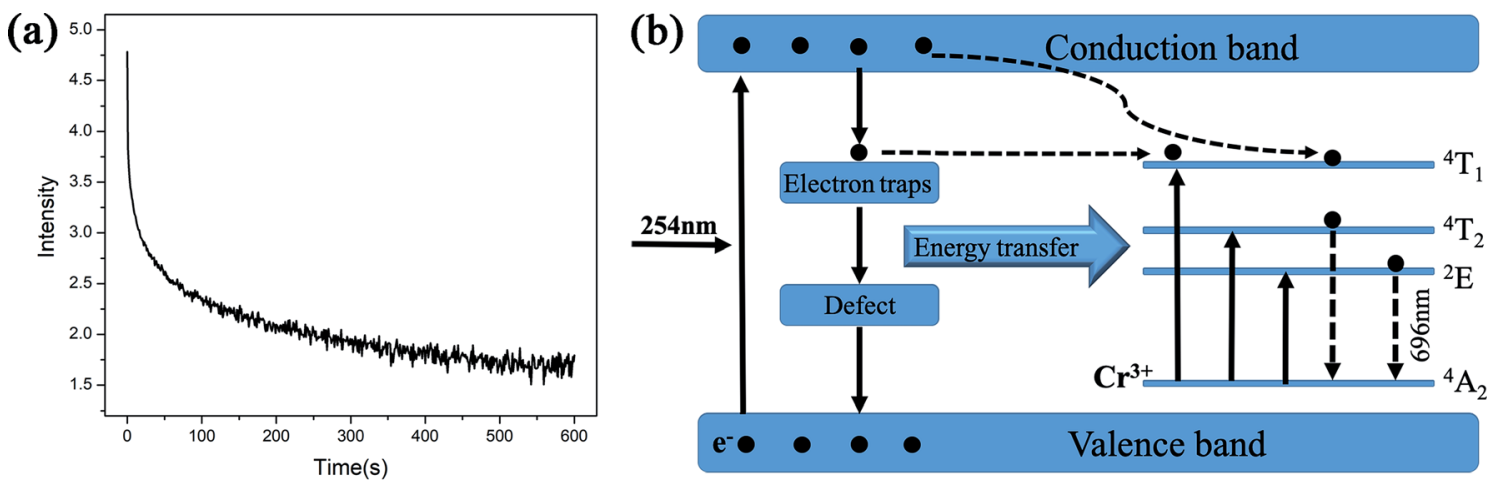

Fig. 6 (a) Photoluminescence decay curve of the $\mathrm{ZnGa}_{2} \mathrm{O}_{4}: \mathrm{Cr}^{3+}$-based aerogel after $800{ }^{\circ} \mathrm{C}$ calcination, (b) the schematic diagram of the energy levels involved in the energy transfer mechanism between $\mathrm{ZnGa}_{2} \mathrm{O}_{4}$ and $\mathrm{Cr}^{3+}$ and the subsequent emission from $\mathrm{Cr}^{3+}$.

Table 1 The fitting parameters and the calculated lifetimes from the $\mathrm{PL}$ decay curves of the $\mathrm{ZnGa}_{2} \mathrm{O}_{4}: \mathrm{Cr}^{3+}$-based aerogel after $800{ }^{\circ} \mathrm{C}$ calcination

\begin{tabular}{llllll}
\hline$A_{1}$ & $\tau_{1}(\mathrm{~s})$ & $A_{2}$ & $\tau_{2}(\mathrm{~s})$ & $\tau(\mathrm{s})$ & $R^{2}$ \\
\hline 7359.79 & 2.69 & 1430.79 & 36.06 & 26.81 & 0.98
\end{tabular}

conduction band to the corresponding trap and captured due to thermal radiation and conduction band assist. The electron traps and hole traps are the energy states of storing excited electrons and holes, the energy can be stored for a period of time. However, after UV irradiation stopped, some electrons will break free from the shallow trap and transfer to the ${ }^{4} \mathrm{~T}_{1}$ energy level of $\mathrm{Cr}^{3+}$. The electrons trapped in the trap center transfer

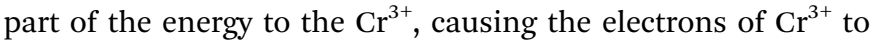
excite from the ground state $\left({ }^{4} \mathrm{~A}_{2}\right)$ to the three excited state levels of ${ }^{2} \mathrm{E},{ }^{4} \mathrm{~T}_{1}$, and ${ }^{4} \mathrm{~T}_{2}$. The excited $\mathrm{Cr}^{3+}$ electrons return to the ground state by emitting photons of different energy. ${ }^{13,25}$ This produces a near-infrared long afterglow phenomenon which attribute to the sustained energy transfer of the host $\mathrm{ZnGa}_{2} \mathrm{O}_{4}{ }^{26}$
The degradation of methylene blue (MB) dye was measured as a function of irradiation time of $\mathrm{ZnGa}_{2} \mathrm{O}_{4}: \mathrm{Cr}^{3+}$-based aerogels, and samples with different calcination temperatures was also tested for comparison. The sample without calcination exhibits high photocatalytic performance with $80.1 \% \mathrm{MB}$ degradation at $20 \mathrm{~min}$, much better than other materials. In addition, it can be seen that the adsorption effect of aerogel is also very good. After 40 minutes in the dark room, the adsorption rate reached $40 \%$. However, the degradation rate of the calcined sample is slower and more uniform. The experimental results show that the heat treatment has a great influence on the photocatalytic and adsorption properties. As the calcination temperature gradually increases, the characteristic surface area of aerogels decrease and the particle volume increases, resulting in a decrease in catalytic activity. The morphology of the samples after calcined were characterized by SEM, as shown in Fig. 7. Obviously, the morphology changes from porous loose dendrites to dense spherical stacked structures. The pore structure almost disappears and the clusters are very tightly bound. This may be due to structural collapse of the sample during calcination. The SEM images are consistent with the conclusion obtained by photocatalytic. To support this
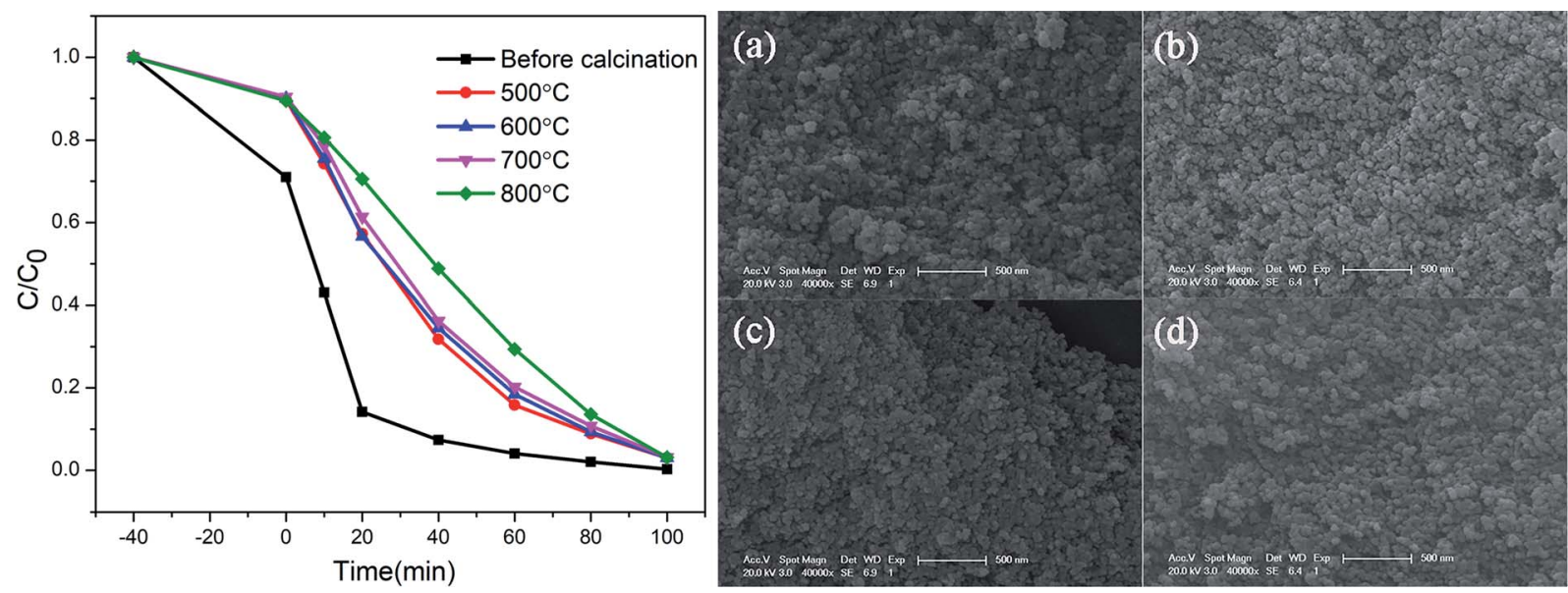

Fig. 7 Photocatalytic effect of $\mathrm{ZnGa}_{2} \mathrm{O}_{4}: \mathrm{Cr}^{3+}$-based aerogels at different calcination temperatures; the SEM images of the samples after (a) $500{ }^{\circ} \mathrm{C}$, (b) $600{ }^{\circ} \mathrm{C}$, (c) $700{ }^{\circ} \mathrm{C}$ and (d) $800{ }^{\circ} \mathrm{C}$ calcination. 

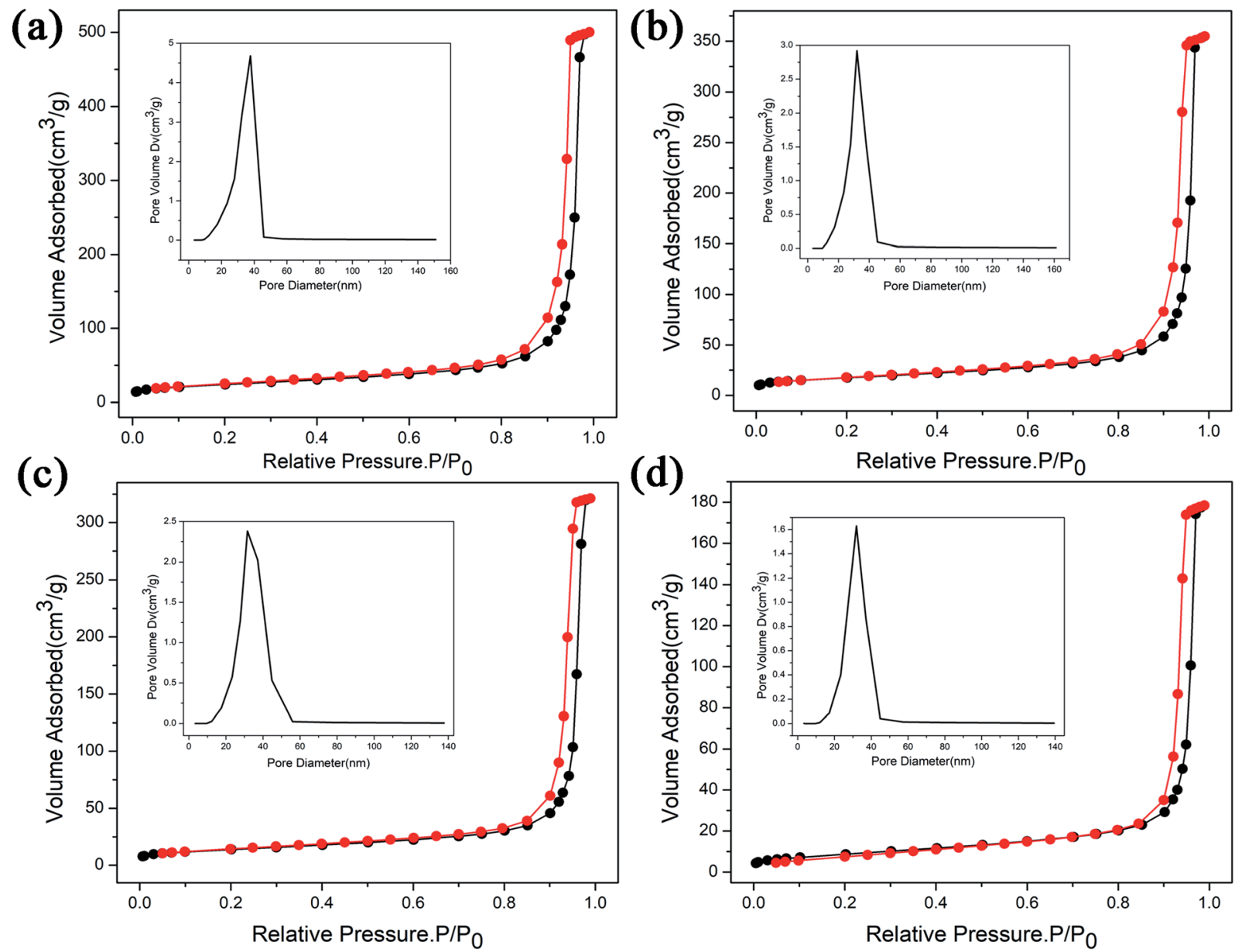

Fig. 8 The $\mathrm{N}_{2}$ adsorption-desorption isotherms of the $\mathrm{ZnGa}_{2} \mathrm{O}_{4}: \mathrm{Cr}^{3+}$-based aerogels with different calcination temperatures, (a) $500{ }^{\circ} \mathrm{C}$, (b) $600{ }^{\circ} \mathrm{C}$, (c) $700^{\circ} \mathrm{C}$, (d) $800^{\circ} \mathrm{C}$, and inset is the pore size distribution of its.

Table 2 The surface area and average pore size of the $\mathrm{ZnGa}_{2} \mathrm{O}_{4}: \mathrm{Cr}^{3+}$-based aerogels with different calcination temperatures

\begin{tabular}{lcccc}
\hline & Before calcined & $500{ }^{\circ} \mathrm{C}$ & $600{ }^{\circ} \mathrm{C}$ & $700{ }^{\circ} \mathrm{C}$ \\
\hline Surface area $\left(\mathrm{m}^{2} \mathrm{~g}^{-1}\right)$ & 420.3 & 84.3 & 61.6 & 48.9 \\
Average pore size $(\mathrm{nm})$ & 14.6 & 36.7 & 35.7 & 30.7 \\
& & & 36.0 \\
\hline
\end{tabular}

conclusion, we characterized the $\mathrm{N}_{2}$ adsorption-desorption isotherms of calcined samples with different temperatures, as shown in Fig. 8. As the temperature increases, the specific surface area of the samples is $84.3 \mathrm{~m}^{2} \mathrm{~g}^{-1}, 61.6 \mathrm{~m}^{2} \mathrm{~g}^{-1}, 48.9 \mathrm{~m}^{2}$ $\mathrm{g}^{-1}, 30.7 \mathrm{~m}^{2} \mathrm{~g}^{-1}$ (Table 2). Compared with Fig. 1(c), it is much reduced, once again proving this conclusion. In addition, photocatalytic and long-lasting luminescence are significantly associated. In the $\mathrm{ZnGa}_{2} \mathrm{O}_{4}$ host, a part of photo-generated electrons and holes recombine to release energy in the form of photoluminescence. And some of them can be trapped by lattice defects, impurities or $\mathrm{Cr}^{3+}$. The photo-generated electrons and holes are trapped to slow down the recombination process, which will enhance charge transfer and photocatalytic activity. On the other hand, after stopping the UV irradiation, some electrons and holes break free from the trap. Transferring part of the energy to $\mathrm{Cr}^{3+}$ and then emitting long-lasting light. It can be seen that the relationship between photocatalytic and long afterglow properties is mutually inhibited. As the calcination temperature increases, the luminescence intensity increases and the photocatalytic efficiency decreases. ${ }^{27}$

\section{Conclusions}

In this work, we have found a novel method to synthesize $\mathrm{ZnGa}_{2} \mathrm{O}_{4}$ : $\mathrm{Cr}^{3+}$-based aerogel via $\mathrm{CO}_{2}$ supercritical drying. The results of BET and SEM show that there is a certain degree of macroporosity $(d>50 \mathrm{~nm})$ in the aerogel. It has a dendritic structure and the interior is relatively loose. EDS mapping illustrates that the elements $\mathrm{Zn}, \mathrm{Ga}$, and Cr evenly distributed in the aerogel. In addition, the XRD, FTIR results and the diffuse 
reflectance spectra demonstrated when the calcination temperature is greater than $600{ }^{\circ} \mathrm{C}$, the sample will exhibit nanocrystalline properties and have a significant emission. The PL spectrum of the sample shows that as the calcination temperature increases, the luminescence intensity increases. Furthermore, this materials exhibit excellent long afterglow performance and high photocatalytic performance with $80.1 \%$ methylene blue (MB) degradation at $20 \mathrm{~min}$. We believe, this aerogel has a significant role in the field of hypervelocity particle capture. This is of great significance for solving the thermal interaction between hypervelocity particles and aerogels.

\section{Conflicts of interest}

There are no conflicts to declare.

\section{Acknowledgements}

We thank the financial support from the National Key Research and Development Program of China (2017YFA0204600) and the National Natural Science Foundation of China (No. 11874284).

\section{References}

1 W. Zhang, J. Zhang, Y. Li, Z. Chen and T. Wang, Appl. Surf. Sci., 2010, 256, 4702-4707.

2 X. L. Duan, D. R. Yuan, L. H. Wang, F. P. Yu, X. F. Cheng, Z. Q. Liu and S. S. Yan, J. Cryst. Growth, 2006, 296, 234-238.

3 X. Duan, J. Liu, Y. Wu, F. Yu and X. Wang, J. Lumin., 2014, 153, 361-368.

4 Q. Shi, C. Wang, D. Zhang, S. Li, L. Zhang, W. Wang and J. Zhang, Thin Solid Films, 2012, 520, 6845-6849.

5 S. Itoh, H. Toki, Y. Sato, K. Morimoto and T. Kishino, J. Electrochem. Soc., 1991, 138, 1509-1512.

6 T. Minami, Y. Kuroi, T. Miyata, H. Yamada and S. Takata, J. Lumin., 1997, 72, 997-998.

7 T. Omata, N. Ueda, K. Ueda and H. Kawazoea, Appl. Phys. Lett., 1994, 64, 1077-1078.

8 I. J. Hsieh, K. T. Chu, C. F. Vu and M. S. Feng, J. Appl. Phys., 1994, 76, 3735-3739.
9 T. Sei, Y. Nomura and T. Tsuchiya, J. Non-Cryst. Solids, 1997, 218, 135-138.

10 I. K. Jeong, H. L. Park and S. Mho, Solid State Commun., 1998, 105, 179-183.

11 N. Avci, K. Korthout, M. A. Newton, P. F. Smet and D. Poelman, Opt. Mater. Express, 2012, 2, 321-330.

12 F. Ye, S. Dong, Z. Tian, S. Yao, Z. Zhou and S. Wang, Opt. Mater., 2013, 36, 463-466.

13 M. K. Hussen, F. B. Dejene and G. G. Gonfa, Appl. Phys. A: Mater. Sci. Process., 2018, 124, 1-10.

14 J. S. Kim, S. G. Lee, H. L. Park, J. Y. Park and S. D. Han, Mater. Lett., 2004, 58, 1354-1357.

15 M. Yu, J. Lin, Y. H. Zhou and S. B. Wang, Mater. Lett., 2002, 56, 1007-1013.

16 A. Bessière, S. Jacquart, K. Priolkar, A. Lecointre, B. Viana and D. Gourier, Opt. Express, 2011, 19, 10131-10137.

17 M. Kruk and M. Jaroniec, Chem. Mater., 2001, 13, 3169-3183.

18 M. Aghajamali, M. Iqbal, T. K. Purkait, L. Hadidi, R. Sinelnikov and J. G. Veinot, Chem. Mater., 2016, 28, 3877-3886.

19 S. K. Sharma, A. Bessière, N. Basavaraju, K. R. Priolkar, L. Binet, B. Viana and D. Gourier, J. Lumin., 2014, 155, 251-256.

20 Y. Zhuang, J. Ueda and S. Tanabe, Appl. Phys. Express, 2013, 6, 052602.

21 Y. Tanabe and S. Sugano, J. Phys. Soc. Jpn., 1954, 9, 766-779. 22 B. B. Srivastava, A. Kuang and Y. Mao, Chem. Commun., 2015, 51, 7372-7375.

23 S. G. Menon, K. S. Choudhari, S. A. Shivashankar, C. Santhosh and S. D. Kulkarni, J. Alloys Compd., 2017, 728, 484-489.

24 J. H. Cha and H. W. Choi, Trans. Electr. Electron. Mater., 2011, 12, 11-15.

25 M. K. Hussen and F. B. Dejene, J. Sol-Gel Sci. Technol., 2018, 88, 454-464.

26 L. Li, Y. Wang, H. Huang, H. Li and H. Zhao, Mod. Phys. Lett. $B, 2016,30,1650019$.

27 L. Li, Y. Wang, H. Li, H. Huang and H. Zhao, RSC Adv., 2015, 5, 57193-57200. 